\title{
Inclusão em educação: processos de avaliação em questão ${ }^{1}$
}

Mylene Cristina Santiago ${ }^{a}$ Mônica Pereira dos Santos ${ }^{b}$

Sandra Cordeiro de Melo ${ }^{c}$

\section{Resumo}

Este trabalho discute os dados do Observatório Nacional da Educação Especial (Oneesp) no Estado do Rio de Janeiro (Oeerj) no que tange ao processo de avaliação e inclusão em educação. Através de entrevistas coletivas e da participação dos professores no ciclo de formação continuada, foram identificadas três diferentes questões: a primeira se trata do diagnóstico do aluno alvo do atendimento educacional especializado; a segunda se refere às políticas avaliativas de larga escala; e a última se trata das necessárias mudanças multidimensionais nas práticas avaliativas no cotidiano escolar. Indicamos que o processo avaliativo é um importante parâmetro para identificar se as propostas pedagógicas possibilitam condições de aprendizagem e participação para todos os estudantes.

Palavras-chave: Formação de professores. Atendimento educacional especializado. Inclusão em práticas de avaliação.

\section{Introdução}

Este trabalho busca apresentar reflexões suscitadas pela pesquisa do Observatório Nacional da Educação Especial (Oneesp) no Estado do Rio de Janeiro (Oeerj) no que tange ao processo de avaliação e inclusão em educação. A pesquisa-matriz (Oneesp), de abrangência nacional, vem sendo desenvolvida, desde 2010, em diversos Estados e municípios brasileiros e envolve instituições de Ensino

\footnotetext{
a Universidade Federal Fluminense. Niterói, Rio de Janeiro, Brasil.

b Universidade Federal do Rio de Janeiro. Rio de Janeiro, Rio de Janeiro, Brasil.

c Universidade Federal do Rio de Janeiro. Rio de Janeiro, Rio de Janeiro, Brasil.

1 Dados da Pesquisa do Observatório Nacional da Educação Especial (Oneesp) no Estado do Rio de Janeiro (Oeerj). Financiamento Capes e Faperj.
} 
Superior de todo o país. No caso do Rio de Janeiro (Oeerj), no ano de 2012, contamos com a participação de 63 professores de educação especial, alguns dos quais também exerciam função, em escolas alternadas, de mediadores e professores de classe regular dos municípios de Niterói, Petrópolis, Nova Iguaçu e Rio de Janeiro, e com o envolvimento da Universidade Federal Fluminense (UFF), Universidade Federal do Rio de Janeiro (UFRJ), Universidade Federal Rural do Rio de Janeiro (UFRRJ) e Universidade do Estado do Rio de Janeiro (UERJ).

O Observatório Estadual, no ano referido de 2012, levou a cabo uma pesquisa colaborativa. Escolhemos este delineamento em consonância com o Observatório Nacional, e porque a mesma permite construir conhecimento "com" os professores e não apenas "sobre" eles (LIEBERMAN, 1986). Deste modo, as relações entre pesquisadores e pesquisados se caracterizaram por uma reflexão-ação conjunta sobre as práticas educacionais com vista a auxiliar professores e gestores a encontrarem formas de transformar as ações pedagógicas (JARDILINO, 2005).

Os dados aqui utilizados foram coletados durante a etapa do "Ciclo de Formação Continuada para Professores das Salas de Recursos Multifuncionais", através da realização de três encontros de grupos focais com esses professores, com vista a discutir os eixos temáticos determinados pelo Observatório Nacional.

Divididos em seis grupos focais, os 63 professores participantes foram instigados, em cada encontro, por meio de um roteiro semiestruturado, a falar sobre os temas propostos pela pesquisa nacional. O segundo encontro, que trabalhou o eixo temático da avaliação do estudante com Necessidades Educacionais Especiais (NEEs), teve três focos de discussão, em que buscamos investigar: como é avaliação para a identificação dos alunos com NEEs; como ocorre a avaliação para o planejamento das atividades que serão realizadas nas SRMs; e como acontece a avaliação da aprendizagem dos alunos.

Assim, para efeito deste trabalho, nos deteremos no eixo discutido durante o segundo encontro do ciclo de formação de professores, com o objetivo de refletir sobre o processo de avaliação no Atendimento Educacional Especializado (AEE) e da escola como um todo, articulando essa temática com nossa perspectiva analítica, fundamentada na interligação entre cinco dimensões: culturas, políticas e práticas (BOOTH, 2011); dialética inclusão/exclusão (SAWAIA, 2008) e complexidade (MORIN, 2006). A esta perspectiva, damos o nome de Omnilética (SANTOS, 2013), e ela fundamenta nossa proposta de trabalho junto aos professores e gestores em formação. 
Em termos sucintos, a perspectiva Omnilética nos permite perceber, explicar e propor, de diferentes maneiras, um mesmo fenômeno (em nosso caso, o da exclusão). Como em um movimento caleidoscópico (FOREST, 1984), novas conformações dos fenômenos - que sugerem novas explicações, investigações, decisões e ações - vão se tornando possíveis. Isto porque, a cada nova mirada na realidade, reconhecemos a complexidade (que é lógica, ética, auto-organizadora e exponencial em possibilidades) e a dialeticidade (totalizante, dinâmica e desveladora) presentes nas relações existentes entre valores e crenças ali embutidos (culturas), nas políticas (intenções e decisões que objetivam orientar ações) e nas práticas sociais (as ações propriamente ditas).

No grupo focal e no ciclo de formação continuada ficaram evidenciadas três problemáticas centrais a respeito da concepção e prática da avaliação: a primeira se trata da questão do diagnóstico do aluno alvo do atendimento educacional especializado; a segunda se refere às políticas avaliativas de larga escala diante das práticas de inclusão que se delineiam nas escolas; e a última questão trata das necessárias mudanças multidimensionais nas práticas avaliativas no cotidiano escolar, de modo a efetivar a participação de todos.

\section{Avaliação no atendimento educacional especializado}

A Política Nacional de Educação Especial na Perspectiva da Educação Inclusiva (BRASIL, 2008) configura o professor do Atendimento Educacional Especializado como profissional da educação com atribuição de identificar, elaborar e organizar recursos pedagógicos e de acessibilidade visando colaborar no processo de inclusão em educação, ou seja, na eliminação de barreiras para a plena participação e aprendizagem dos alunos, considerando suas necessidades específicas.

Identificamos que uma preocupação recorrente com a avaliação no atendimento educacional especializado trata-se da questão da identificação do aluno a ser atendido e encaminhado para a sala de recursos multifuncionais (SRM). Em alguns contextos, há exigência de um diagnóstico clínico (dimensão política) para o ingresso do aluno no Atendimento Educacional Especializado. Todavia, segundo as orientações para o preenchimento do Censo Escolar referente ao ano de 2011 (omnileticamente falando, eis aqui uma dimensão política, caracteristicamente dialética e complexa: uma política contrapõe a outra, permitindo a instauração de uma subcultura - em certas exceções, os valores/critérios são outros - que, por sua vez, afeta a dimensão das práticas), essa exigência é relativizada em um parecer pedagógico emitido pelo professor do atendimento educacional especializado, que viabiliza a inserção do aluno nas SRM. Nesse contexto, conforme observação de Bridi (2012, p. 501), 
A avaliação inicial e o parecer pedagógico do professor do Atendimento Educacional Especializado ganham relevância e passam a sustentar o processo decisório sobre o ingresso do aluno no serviço, bem como, sua inserção como aluno do público alvo da educação especial no Censo Escolar MEC/INEP.

Ao discutirem o processo de avaliação e de encaminhamento dos alunos para o atendimento educacional especializado, as professoras participantes da pesquisa OEERJ revelaram os contextos vivenciados e o grau relativo de autonomia dos professores do AEE nesse processo, conforme transcrição abaixo:

As escolas têm e não têm autonomia, porque, na verdade, tem o agente (Agente Pedagógico de Educação Especial) que vai à escola e que avalia, e ele vai definir quem vai ser atendido no atendimento educacional especializado ou não. [...] Quem define isso é a coordenação de educação especial, isso independe do laudo, às vezes, a criança tem laudo e ela não precisa de atendimento educacional especializado e, às vezes, ela não tem laudo e precisa, então, isso normalmente é definido pela coordenação, mas tem, vamos dizer assim, uma parceria com a escola. (Professora C)

Mesmo que exista a possibilidade de o professor do AEE emitir um laudo pedagógico para que o aluno possa ser inserido nas SRM, a preocupação com o laudo médico é contínua e central, principalmente em casos em que a deficiência não é aparente, conforme relato:

Porque no caso de alunos que têm uma deficiência física, ele vai ter um critério para ser avaliado, isso é notório. Ele vai ter um critério, porque você está vendo que ele tem uma deficiência, é deficiente físico. Então, nesse caso, ele é imediatamente encaminhado para a sala de recursos. Agora, no caso de outros deficientes, por exemplo, o aluno que tenha TGD, o aluno DI, o aluno DA, um surdo, ele vai ter outro critério, porque ele vai precisar também de um parecer médico, né, de uma avaliação mais profunda. (Professora M)

Embora a Nota Técnica $n^{\circ}$ 04/2014 (BRASIL, 2014) reconheça que a existência de um laudo médico não seja condicionante para a inserção do aluno nas SRM, uma vez que o AEE se caracteriza por atendimento pedagógico e não clínico, há um sentimento 'autocoercitivo' por parte dos profissionais de que o aluno 
só pode ser computado no censo escolar caso tenha um laudo legitimado pelos saberes médicos-clínicos:

[...] O laudo, na verdade, ele não é condicionante e não deve ser condicionante para matricular, mas, muitas vezes, a escola maquia e exige uma condição de matrícula a partir do laudo. [...] Ainda há dificuldade na área médica pra nos esclarecer acerca de qual deficiência que aquela criança tem, então, a questão do laudo para a gente é uma faca de dois gumes. [...] Eu, gestora, vou responder a um senso do MEC que fatidicamente coloca as pessoas com deficiência em caixinhas: deficiência visual, deficiência mental, deficiência intelectual, isso é terrível, entendeu? (Professora A)

O laudo da sala de recurso pra gente, ele é dispensável. O aluno entrou na escola, tem o comprometimento, está na sala de recurso. Agora, a título governamental, para que o aluno seja encaixado na famigerada caixinha do MEC e botado no senso, a gente precisa deste laudo, infelizmente. (Professora D)

Concordamos que a prudência no momento de emitir hipóteses ou conclusões (dimensão das práticas) que possam identificar ou rotular (culturas) alunos em relação à existência de determinada deficiência e/ou transtorno é legítima no campo pedagógico (políticas). Entretanto, questionamos se os laudos emitidos pelos serviços médicos e de saúde são incontestáveis. O relato abaixo ilustra nossa preocupação:

Às vezes, a gente esbarra em um mesmo laudo para todas as crianças, a mesma medicação para todas as crianças com características diferentes, e isso, não que impeça o nosso trabalho, mas a gente começa a se questionar se essa intervenção médica é propícia para a aprendizagem dessa criança. (Professora P)

Nos casos em que as diferenças/deficiências podem não ser percebidas imediatamente, há uma 'insistência' (culturas e práticas) na obtenção de laudo e, em alguns casos, ocorre até mesmo uma pressão sobre a família (práticas) do aluno no processo de obtenção desse laudo com o diagnóstico da deficiência ou do transtorno do aluno:

Como tem o caso de uma (deficiência) que, aparentemente, não podemos falar que tem, pois não somos da equipe médica. Com 
hidrocefalia, se tem uma baixa visão, visivelmente tem uma baixa visão, uma deficiência intelectual, tem comprometimento na marcha. Então, essas crianças que visivelmente apresentam uma necessidade educacional especial ou alguma deficiência, elas vão diretamente para nossa sala. (Professora S)

O período de avaliação depende mais da área da saúde do que da educação, porque nós fazemos a avaliação mais rápido possível. O problema é que, às vezes, os responsáveis demoram seis meses para um agendamento para o neuropediatra, por exemplo, ou sei lá quantos meses, quantos anos, na fila esperando atendimento fonoaudiológico? Bom, não sei, enfim, isso é mais demorado, em casos mais graves, a gente abre algumas exceções e encaminha para a sala de recurso, mas nem sempre isso acontece, geralmente a gente pressiona para que consiga obter esse laudo. (Professora T)

Omnileticamente, percebemos, neste exemplo, uma série de mecanismos culturais, políticos e práticos de relação dialética e complexa. É da dimensão cultural não querer o laudo, como também o é querê-lo, o que, em si mesmo, aponta para interesses variados em jogo (dialeticidade) e para a complexidade presente nas "soluções" dadas a cada caso, tendo em vista que, conforme os mesmos, as probabilidades de novos caminhos vão aumentando e gerando novas situações. São da dimensão política as orientações que tanto privilegiam o laudo médico quanto as que "abrem a brecha" para o laudo pedagógico. Mais uma vez, as decisões (políticas) acerca dos caminhos a seguir (práticas) revelam os interesses variados (culturas e políticas) em jogo, como também os variados dispositivos de legitimação (políticas e culturas) e auto-organizadores presentes conforme as necessidades, que, por sua vez, apontam para novas possibilidades de configurações e combinações de decisões (políticas) e ações (práticas) e/ou remetem a uma revisão dos valores (culturas) que os inspiraram (dialeticidade e complexidade). É da dimensão das práticas seguir um ou outro, ou ambos, dependendo do caso em questão (culturas e políticas), ou mesmo assumir caminhos que se contradizem simultaneamente (dialeticidade e complexidade), inspirando a uma revisão de novas culturas, políticas e práticas.

De forma similar ao estudo realizado por Bridi (2012), identificamos que os profissionais do AEE do Estado do Rio de Janeiro também vivenciam situações de angústia diante do contingente de alunos que, segundo os olhares escolares, são vistos como sujeitos com dificuldades de aprendizagem, de construção do 
conhecimento sistematizado, com dificuldades vinculadas ao aspecto cognitivo. Em suas narrativas, nossas professoras expressam que:

No início, até por falta de crianças, vamos dizer assim, especiais para o atendimento, nós atendíamos até crianças com dificuldade de aprendizado, que eram as crianças que estavam com 14 anos e ainda não tinham sido alfabetizadas, mas aparentemente sem nenhuma deficiência. (Professora N)

[...] Temos uma dificuldade de parceria com a questão médica de conseguir o laudo, ao mesmo tempo em que temos médicos que não dão laudo, às vezes, temos médicos que dão laudos demais, então, está acontecendo de chegarem muitos alunos com laudos de "transtorno do aprendizado" e, às vezes, é uma questão que vemos não necessitar do atendimento educacional especializado, precisa de uma atenção pedagógica. Pedagogicamente, o professor consegue resolver na sala de aula. (Professora C)

O AEE tem seu público alvo claramente explicitado: alunos com deficiência, altas habilidades/superdotação e transtornos globais do desenvolvimento. Desse modo, barreiras à aprendizagem não são situações consideradas para atendimento nas SRMs, assim como há casos de alunos com deficiência que não se beneficiariam desse atendimento pedagógico, conforme explicitado:

Temos uma criança com hidrocefalia que não teve sequelas da hidrocefalia, ela tem a válvula e tudo mais, mas o cognitivo dela é preservado, não tem a deficiência motora, não tem nenhuma sequela dessa hidrocefalia. O professor sabe dos cuidados quem tem que ter com essa aluna, mas não precisa do AEE. (Professora D)

[...] Em alguns casos é só caso de dificuldade de aprendizagem e [a criança] não entra na sala de recurso e passa a ser incluída, mas, mesmo assim, a gente tem feito um trabalho com os professores para ter um trabalho diferenciado com essa criança, por mais que ela não possa ter esse atendimento, mas os professores estão se conscientizando de ter um olhar diferenciado. (Professora G)

Reconhecemos que as principais barreiras evidenciadas no processo de escolarização dos alunos com deficiência e com outras diferenças (cognitivas, comportamentais, culturais...) são relativas às dificuldades dos professores de 
sala de aula (políticas e práticas) regular em oferecer respostas educativas às suas demandas específicas, assim como barreiras atitudinais (culturas) que se traduzem em preconceitos e processos de discriminação. Por outro lado, omnileticamente, questionamos: em que medida tais barreiras dependem somente de uma decisão (política) pessoal? Não seriam as atuais formas de organização (política) das nossas redes educacionais impeditivas, ou dificultadoras de práticas de inclusão, tendo em vista que tanto as políticas do sistema educacional como as institucionais contradizem-se, mostram brechas interpretativas e sabotam, de certo modo, aquilo mesmo que defendem no discurso, surtindo novas oportunidades de questionamento, revisão e formulação de outras políticas, culturas e práticas, por sua vez (dialeticidade e complexidade)?

É consenso que os alunos alvo da educação especial fogem aos padrões considerados como normalidade, conforme explicitado na própria política (BRASIL, 2008). São alunos que apresentam deficiências, ou altas habilidades, ou transtornos globais do desenvolvimento. Então, necessariamente, se exercermos sobre eles a lógica de processos avaliativos dominantes, excludentes e classificatórios, ampliaremos as condições de desigualdades em vez de garantirmos oportunidades justas.

Diante dessa problemática, preocupadas com a especificidade do processo avaliativo, questionamos como desenvolver e avaliar suas potencialidades? Qual o papel da avaliação no AEE e na escola? Qual o objetivo dos processos avaliativos? Seria examinar o aluno? Seria verificar a aprendizagem ou a não aprendizagem dele? Ou a avaliação seria um recurso para replanejar a proposta de ensino, diante da identificação de barreiras nos processos de aprendizagem e de participação de nossos alunos? Defendemos que, em uma perspectiva de inclusão, as avaliações, sejam dos alunos, dos profissionais da escola, ou mesmo da instituição como um todo, jamais podem ser punitivas, como lamenta Freire (1997, p. 11): "Avaliamos para punir e não para melhorar a ação e a formação dos sujeitos".

\section{Barreiras que transcendem os muros escolares: a avaliação de larga escala}

Historicamente, a escola tem sido 'indiferente às diferenças' (BOURDIEU; PASSERON, 2008). Sob o prisma da igualdade, criamos mecanismos homogêneos para todos. Se acreditarmos que tratar os alunos de forma igual é oferecer as mesmas oportunidades, as mesmas avaliações, o mesmo currículo, para quem apresenta diferenças, é certo que estaremos produzindo situações de desigualdades. 
Considerar o contexto sociocultural dos alunos é premissa básica que todos conhecem, mas poucos praticam no cotidiano didático. A partir do momento em que oferecermos um processo de ensino-aprendizagem contextualizado, uma estrutura de aprendizagem que tenha mais relação com a vida, com a experiência do próprio aluno, é possível modificarmos as culturas, políticas e práticas (BOOTH; AINSCOW, 2012) existentes em nossa instituição educacional.

Inclusão é, portanto, processo infindável que precisa ser pensado, de forma coletiva e contextualizada, no cotidiano escolar. Uma proposta de inclusão em educação implica assumir novas lógicas no plano individual, coletivo e institucional, no que tange às dimensões anteriormente mencionadas. De acordo com Drago (2013), inclusão é um conceito que emerge da complexidade e exige novo modo de organização do sistema educacional. Nas suas palavras:

Entender que existem barreiras que precisam ser transpostas, que métodos e técnicas precisam ser revistos e que o ensino coletivo pode ser um caminho interessante para o sucesso da inclusão são possibilidades para que o processo inclusivo deixe de ser algo apregoado pela legislação e passe a ser parte do dia-a-dia escolar. (DRAGO, 2013, p. 64)

Uma barreira constantemente trazida pelo grupo de professoras do atendimento educacional especializado se refere à participação dos nossos discentes com deficiência nos testes das avaliações de larga escala. Os sistemas de avaliação em larga escala do governo federal têm como objetivo subsidiar a elaboração de diagnósticos sobre a realidade educacional e orientar a elaboração de políticas com vista à melhoria da qualidade do ensino. De forma omnilética, as professoras contestam a concomitância de políticas de educação especial e de avaliação que expressam a contraditória relação inclusão/exclusão, na medida em que suas ações indicam descompasso na real garantia do acesso, participação e aprendizagem de alunos com deficiência na escola, o que inclui, com efeito, sua efetiva participação em processos avaliativos de larga escala. De acordo com Cardoso e Magalhães (2013, p. 3):

Um sistema público de ensino, seja ele qual for, é descrito por sua heterogeneidade. Os alunos de um sistema educacional como o brasileiro são essencialmente diversos, em um país com dimensões e disparidades regionais inegáveis. Quando nos referimos ao grupo de alunos com deficiência estamos, também, diante de um grupo diverso, com necessidades específicas de acessibilidade escolar. 
Enquanto alguns necessitam de recursos diferenciados para poderem ser avaliados adequadamente, outros necessitam de processos de flexibilização das formas de avaliação. Ou seja, traduzir uma atividade de avaliação para o Braille para um garoto de oito anos, tem aspectos bastante diferentes dos processos avaliativos destinado a outro garoto, da mesma idade, que tenha Síndrome de Down.

Os processos de avaliação em larga escala, analisados omnileticamente, colocam em questão a dinâmica de escolarização dos alunos com deficiência, revelando práticas de exclusão. Silva e Melletti (2012), ao investigarem dados da Prova Brasil e do Enem de 2007, disponibilizados pelo Instituto Nacional de Estudos e Pesquisas Educacionais Anísio Teixeira (INEP), evidenciaram que o número de matrículas de alunos com NEE é bastante superior ao número de alunos que realizam estas avaliações em larga escala, e que à medida que se avança na escolarização, o número de matrículas de alunos com necessidades educacionais especiais reduz drasticamente. No Estado do Rio de Janeiro, esta situação se confirma conforme relatos a seguir:

Os que têm laudo não fazem prova, senão o rendimento da escola cai. Então, eles não fazem as provas institucionais como a Provinha Brasil. Eles fazem outros tipos de avaliações internas. As avaliações são adaptadas, dentro da limitação deles, porque tem criança que não tem condição nenhuma. (Professora N)

A orientação é que os alunos participem das avaliações sim, mas a gente sabe que isso, às vezes, não.... Nem sempre acontece, a gente tem relatos de que isso nem sempre acontece, e esses alunos fazem uma outra atividade nesse momento. (Professora C)

A concepção de exame (cultura), configurada a partir de padrões (política) que estimulam a uniformização (prática) dos processos e dos resultados (por conta da dialeticidade e complexidade entre cultura, política e prática - ora conflitantes, ora concordantes; ora simultâneas, ora escalonadas; ora perceptíveis, ora implícitas e mesmo veladas...) molda as práticas pedagógicas, reduzindo as possibilidades de estímulo à diferença, que poderia ser tão característica da sala de aula. Conforme Esteban (2008), esse quadro legitima as desigualdades decorrentes das diferenças, fragmenta e distancia os sujeitos de seu processo de ensino-aprendizagem e enfatiza o resultado. Nesse contexto, os professores acreditam que a avaliação deve ser diferenciada, adaptada, ou, até mesmo, facilitada para os estudantes com deficiência, o que favorece a verificação da aprendizagem, sem, contudo, 
focalizar as estratégias e propostas para o aluno aprender. De acordo com Carneiro (2012, p. 524),

O que precisa ser adaptado são os instrumentos de avaliação, da mesma forma como outros recursos pedagógicos utilizados para o ensino de conteúdos de diferentes áreas do conhecimento. Tais instrumentos devem ser adequados às possibilidades de comunicação dos alunos. Assim, um aluno cego deve ter seus instrumentos de avaliação da aprendizagem adequados à sua condição sensorial diferenciada em relação aos demais. As adequações vão depender da trajetória escolar de cada aluno.

A Nota Técnica nº 08/2011 (BRASIL, 2011) oferece orientação para promoção de acessibilidade nos exames nacionais, afirmando que:

Os órgãos federais, municipais e estaduais, ao aplicarem exames de avaliação institucional ou de desempenho estudantil, devem assegurar as condições necessárias para o pleno acesso e participação de estudantes com deficiência, considerando os princípios da acessibilidade e possibilitando a todos condições de igualdade para a realização desses processos. [...] Tais recursos podem englobar desde a ampliação do tempo, até a disponibilização de recursos de tecnologia assistiva. $\mathrm{O}$ atendimento preferencial, assim como, a presença de profissionais intérpretes de LIBRAS e guia intérprete, devem ser previstos, para recepcionar e orientar os candidatos usuários de Libras, Libras tátil, alfabeto dactilológico tátil ou tadoma. (BRASIL, 2011, p. 107)

O processo de inclusão em educação pressupõe a participação dos alunos em todas as atividades escolares. Para que isso se efetive, se faz necessário pensar estratégias e práticas pedagógicas de forma coletiva, de modo que os atores escolares sejam responsáveis pelo processo de ensino-aprendizagem de todos os alunos, visto que a presença de estudantes com deficiência na escola tensiona ainda mais os processos de ensino-aprendizagem e de avaliação.

Cardoso e Magalhães (2012) denunciam os sistemas de avaliação da atualidade, que apresentam características excludentes que, pelo seu caráter classificatório e seletivo, são incompatíveis com o direito de todos à educação. De acordo com as autoras (apud SOUSA, 2009, p. 34) os principais problemas dessa proposta de avaliação são: 
[...] ênfase nos produtos ou resultados; atribuição de mérito a alunos, instituições ou redes de ensino; dados de desempenho escalonados, resultando em classificação; dados predominantemente quantitativos; destaque à avaliação externa não articulada à auto-avaliação.

A avaliação perpassa todo o processo de ensino-aprendizagem e não pode ser pensada de forma distinta de como concebemos todo o percurso (omnileticamente, levando em conta o todo em suas partes e as partes em seu todo), com o objetivo de construir estratégias de ensino considerando as singularidades (também omniléticas) dos alunos. Conforme Christofari e Baptista (2012, p. 387-8):

Considerar a possibilidade da avaliação da aprendizagem tornar-se estratégia de inclusão escolar é colocar em movimento outros modos de pensar a educação, é desafiar a reformulação dos objetivos da prática de avaliar com questionamentos que buscam encontrar estratégias de ensino adequadas às especificidades de cada aluno e de cada turma. É pensar a avaliação como mapa que vai indicando rotas alternativas, caminhos outros, sem definições prévias, apenas possibilidades.

Para Baptista (2013), as barreiras que envolvem a cognição, o pensamento, a abstração, a comunicação e a interação social desafiam os modos como instituímos nossas práticas, como elaboramos nossos planejamentos e realizamos nossas avaliações. Os alunos alvo do atendimento educacional especializado tornam visíveis as barreiras vivenciadas por outros alunos sem essa identificação. Refletir sobre como ensinamos e como aprendem esses alunos nos ajuda a ensinar melhor e a favorecer que os alunos em geral sejam colocados em condição de aprender. A ideia é que o processo de inclusão beneficie todos os alunos em processo de ensino-aprendizagem.

\section{A avaliação no cotidiano escolar: atores e processos}

Uma perspectiva de inclusão em educação pressupõe considerar as particularidades e potencialidades de cada sujeito como eixo central na ação pedagógica. O processo de inclusão rompe com estigmas educacionais que naturalizam o fracasso. $\mathrm{O}$ entendimento desse processo efetiva, no contexto educacional, a ideia de ambientes dinâmicos e estimulantes para todos os alunos em suas diferenças.

Outro elemento importante no processo de inclusão é compreender que alunos com deficiência são de responsabilidade coletiva dos atores da escola, portanto, a construção de respostas educativas diversificadas compete tanto aos professores 
das salas de aula comum como ao professor do atendimento educacional especializado, como, principalmente, do engajamento de gestores, funcionários, alunos e famílias em prol de um projeto emancipador para a escola e os cidadãos que ela forma.

De acordo com as diretrizes da Política Nacional de Educação Especial, a avaliação pedagógica é definida como:

[...] processo dinâmico que considera tanto o conhecimento prévio e o nível atual de desenvolvimento do aluno quanto as possibilidades de aprendizagem futura, configurando uma ação pedagógica processual e formativa que analisa o desempenho do aluno em relação ao seu progresso individual, prevalecendo na avaliação os aspectos qualitativos que indiquem as intervenções pedagógicas do professor. No processo de avaliação, o professor deve criar estratégias considerando que alguns alunos podem demandar ampliação do tempo para a realização dos trabalhos e o uso da língua de sinais, de textos em Braille, de informática ou de tecnologia assistiva como uma prática cotidiana. (BRASIL, 2008, p. 23)

Em uma análise omnilética, é perceptível que, a despeito de orientações e determinações legais, nossos alunos são submetidos, cotidianamente, a práticas avaliativas dominantes que atuam no sentido de homogeneizar comportamentos e conhecimentos, consolidando a concepção de unicidade de significados, colocação esta já feita, aliás, por Freitas (2008) e também constatada nas palavras da professora de AEE, transcritas a seguir:

Eu tenho alunos que são considerados os piores da escola. Eles já têm necessidades especiais, dentro de turmas agitadas... então, a dificuldade aumenta muito. Então, o que alguns professores têm feito como medida de punição pra essas turmas? Provas dificílimas. Então, esses alunos têm dificuldade com essas provas. Quando eu faço as minhas, eu converso com eles, até mudo meus horários. Entro em acordo com a diretora e troco meu horário. Vou de manhã pra ter essa conversa com os professores, passo a situação desses alunos, que eles têm direito a uma avaliação diferenciada. O meu trabalho é esse: de produzir trabalhos, tudo que possa servir pra ajudar esse aluno em sala de aula. Só que o grupo é muito resistente. (Professora V) 
Como estabelecer parâmetros justos e de inclusão no processo de avaliação? Estamos preparados para romper com parâmetros comparativos entre os discentes, que na prática avaliativa se convertem em notas e conceitos individuais? É possível avaliar de forma diferenciada cada discente? Tais questionamentos nos impulsionam a pensar em possíveis mudanças nas culturas, políticas e práticas que vimos tratando ao longo de nossa argumentação. Tais mudanças seriam resultados da transição do processo de avaliação como práticas classificatórias para práticas de investigação (ESTEBAN, 2013).

Avaliar potencialidades significa, omnileticamente, investigar os caminhos percorridos pelos discentes e criar novos percursos de acordo com as necessidades e possibilidades apresentadas no processo de construção dos conhecimentos. A avaliação, ao assumir um caráter investigativo, se torna dialógica e passível de interpretações múltiplas, se revelando como instrumento problematizador do processo de ensino-aprendizagem e posicionando os professores como pesquisadores de sua prática, para que consigam encontrar respostas possíveis que não se limitam ao certo e errado. Nas palavras de Esteban (2013, p. 97),

A avaliação tem estreita relação com a interpretação que o(a) professor(a) faz das respostas dadas, especialmente significativa no caso das crianças que chegam à escola, portanto, estruturas de compreensão diferentes daquelas aceitas pela norma estabelecida.

Ao trabalhar a questão da inclusão na multidimensionalidade: culturas, políticas e práticas dialética e complexamente inter-relacionadas, deparamo-nos com o seguinte questionamento: como transformar o processo de avaliação numa prática inclusiva, imersos em um modelo cultural onde a avaliação é predominantemente um dispositivo de exclusão? Para mudarmos nossas práticas, precisamos modificar nossas concepções. Christofari e Baptista (2012) nos propõem não pensar em uma avaliação que seja específica para alunos com deficiência, mas problematizar de que maneira, por meio de quais práticas, podemos possibilitar outros entendimentos, construir estratégias de ação pedagógica pautadas na perspectiva da inclusão escolar, ou seja, pensar a avaliação com uma concepção que se orquestre em uma prática que produza estratégia de intervenções pedagógicas para todos.

Na situação narrada em seguida, verificamos que a avaliação de um aluno envolve várias situações e atores (professor, mediadora, familiar...), e está vinculada a todas as etapas de um planejamento de ensino: formulação de objetivos, seleção de conteúdos e recursos, contexto da turma, entre outros: 
Eu sou mediadora de um autista do segundo segmento. A avaliação dele depende também do professor. Numa sala de 20 e poucos alunos, 30 alunos, o professor tem que saber não só da turma, mas dele também. Na escola onde eu trabalho com ele, um professor faz essa adaptação da avaliação, basicamente um, que é o de História, que sabe que ele não pode ler muito texto. Ele faz uso de imagens. [...] Esse ano, foi a primeira vez que esse aluno recebeu o boletim, e a avó dele ficou super feliz. Só que, assim, além do boletim, que é a nota que ele faz por merecer, ele também é avaliado por um relatório. Então dá pra ver esses dois pesos. (Professora P)

Analisar omnileticamente a avaliação escolar, nos possibilita articulá-la com o processo de inclusão no cotidiano escolar, incentivar a participação coletiva e o desenvolvimento contínuo da instituição como características principais. Nessa perspectiva, a mudança de concepção sobre o processo de avaliação assinala estratégias que possam ajudar alunos e professores a compreender e intervir no processo coletivo de construção de conhecimentos.

\section{Considerações para continuar nossas reflexões: inclusão é processo...}

A avaliação permeia (ou deveria permear) todo o processo de ensino-aprendizagem. Em termos didáticos, ao elaborar o plano de aula ou o planejamento de curso, é preciso considerar os nossos objetivos (culturas), nossa intenção (políticas) com o grupo, o contexto do grupo (dialeticidade e complexidade) com o qual iremos trabalhar (práticas). No momento em que estabelecemos objetivos, esses objetivos serão avaliados ao longo do processo. A avaliação (especialmente se feita em uma perspectiva omnilética, ou, pelo menos, mais ampla e politizada) se trata de um instrumento para identificar se estamos no caminho certo, ou seja, o processo avaliativo não se restringe apenas a identificar o aprendizado do aluno, mas nos serve de parâmetro para identificar se nossa proposta pedagógica está possibilitando condições de aprendizagem e participação de todos no processo de ensino-aprendizagem.

Consideramos que as dimensões de culturas, políticas e práticas de inclusão e seus entrelaçamentos dialéticos e complexos nos possibilitam perceber a heterogeneidade como elemento indispensável para o enriquecimento das interações em sala de aula. A relação que estabelecemos com as diferenças em sala de aula é fundamental, pois diferenças assumidas como oportunidades são intimamente relacionadas às dimensões explicitadas, ou seja, da negação das 
diferenças passamos ao reconhecimento das mesmas. Esse deslocamento de olhar e atitude permite que possamos apostar nas potencialidades que cada ser humano possui, independente dos prejuízos resultantes de uma diferença/deficiência.

Nesse contexto, a diferença/diversidade pode ser, ao invés de um problema, como ainda é comumente vista, uma fonte de riqueza e de enriquecimento das nossas práticas sociais, culturais e pedagógicas. Assim, o processo de inclusão em educação, visto pela lente omnilética, problematiza questões referentes à organização curricular, espaços e tempos escolares, estratégias didático-pedagógicas, modos de ensinar e aprender para possibilitar o direito à aprendizagem e à participação para todos. 


\section{Inclusion in education: discussing evaluation processes}

\section{Abstract}

The present paper discusses the data originated from a research entitled Rio de Janeiro's State Observatory of Special Education (Oeerj), which is part of a broader research, named National Special Education Observatory (Oneesp), with regards to the process of evaluation and inclusion in education. Through focus groups carried out during a Continued Education Cycle originated by the State Observatory, we identified three different topics for discussion. The first is linked to processes of identification and diagnosis of the special education student. The second relates to the large-scale evaluation policies. The third has to do with a much needed multidimensional change in the evaluation practices of school routine. We point out that the evaluative process is an important parameter on the basis of which to identify pedagogic practices that make it possible to build learning and participation conditions for all students.

Keywords: Teacher education. Special educational service. Inclusion in evaluative practices.

\section{Inclusión em educación: procesos de evaluación en cuestión}

\section{Resumen}

Este documento analiza los datos que surgen de la investigación del Centro Nacional para la Educación Especial (Oneesp) en el Estado de Río de Janeiro (Oeerj) con respecto a la evaluación y la inclusión en la educación. A través de entrevistas y de la participación de los docentes en el ciclo de educación continua se ha identificado tres cuestiones diferentes: la primera se trata de la cuestión del diagnóstico del estudiante blanco de los servicios educativos especializados; la segunda se refiere a las politicas de evaluación de grande escala; y el último tema, se trata de los cambios multidimensionales necesarios en las prácticas de evaluación en la vida escolar cotidiana. Tomamos nota de que el proceso de evaluación es un parámetro importante para determinar si las propuestas educativas permiten condiciones para el aprendizaje y la participación de todos los estudiantes.

Palabras clave: Formación del profesorado. Servicios educativos especializados. Inclusión en las prácticas de evaluación. 


\section{Referências}

BAPTISTA, C. R. Tornar-se: trajetórias de alunos e formação de professores. In: VITOR, S. L; DRAGO, R; PANTALEÃO, E. Educação especial no cenário educacional brasileiro. São Carlos: Pedro \& João, 2013. p. 15-30.

BRASIL. Ministério da Educação. Secretaria de Educação Continuada, Alfabetização, Diversidade e Inclusão. Nota Técnica $N^{\circ} 04$ / 2014 / MEC / $S E C A D I / D P E E$, de 23 de janeiro de 2014. Orientação quanto a documentos comprobatórios do cadastro de alunos com deficiência, transtornos globais do desenvolvimento e altas habilidades/superdotação no Censo Escolar. Brasília, DF, 2014.

. Ministério da Educação. Secretaria de Educação Especial. Nota Técnica $N^{o} 08$ / 2011 / MEC / SEESP / GAB, de 20 de abril de 2011. Orientação para promoção de acessibilidade nos exames nacionais. Brasília, DF, 2011.

. Ministério da Educação. Secretaria de Educação Especial. Política Nacional de Educação Especial na perspectiva da educação inclusiva. Brasília. DF, 2008.

BOOTH, T.; AINSCOW, M. Index para a inclusão em educação: desenvolvendo a participação e a aprendizagem nas escolas. Rio de Janeiro: LaPEADE, 2011.

BOURDIEU, P.; PASSERON, J. C. A reprodução: elementos para uma teoria do sistema de ensino. Petrópolis: Vozes, 2008.

BRIDI, F. R. S. Avaliação inicial no atendimento educacional especializado: dilemas e consequências. Revista Educação Especial, v. 25, n. 44, p. 499-51, set./dez. 2012. http://doi.org/10.5902/1984686X6951

CARDOSO, A. P. L. B.; MAGALHÃES; R. C. B. P. Educação especial no contexto da política de avaliação em larga escala: a realidade de um município do nordeste brasileiro. In: REUNIÃO NACIONAL DAANPEd, 36., 2013, Goiânia. Anais... Rio de Janeiro: Anped, 2013. Disponível em: $<$ http://36reuniao.anped.org.br/pdfs_trabalhos_aprovados/gt15_trabalhos pdfs/gt15_3319_texto.pdf>. Acesso em: 20 jan. 2014.

. Educação Especial e avaliações em larga escala no município de Sobral (CE). Revista Educação Especial, v. 25, n. 44, p. 449-64, set./dez. 2012. http://doi.org/10.5902/1984686X6535 
CARNEIRO, M. S. C. Reflexões sobre a avaliação da aprendizagem de alunos da modalidade Educação Especial na Educação Básica. Revista Educação Especial, v. 25, n. 44, p. 513-30, set./dez. 2012. http://doi.org/10.5902/1984686X7190

CHRISTOFARI, A. C.; BAPTISTA, C. R. Avaliação da aprendizagem: práticas e alternativas para a inclusão escolar. Revista Educação Especial, v. 25 , n. 44, p. 383-98, set./dez. 2012. http://doi.org/10.5902/1984686X6533

DRAGO, R. Práticas pedagógicas, inclusão e linguagem nos anos iniciais do ensino fundamental. In: VITOR, S. L; DRAGO, R; PANTALEÃO, E. Educação especial no cenário educacional brasileiro. São Carlos: Pedro \& João, 2013. p. 63-82.

ESTEBAN, M. T. O que sabe quem erra?: reflexões sobre avaliação e fracasso escolar. 7. ed. Petrópolis: De Petrus, 2013.

. Provinha Brasil: reeditando a velha confusão entre avaliação e exame. Nuevamerica, n. 118, p. 72-5, 2008. Disponível em: $<$ http://www.novamerica.org. br/Revista_digital/L0118/rev_emrede03.asp >. Acesso em: 1 fev. 2014.

FOREST, M. Full inclusion is possible. In: . Education/ integration: a collection of readings on the integration of children with mental handicaps into the regular school system. Downsview: Institut Roeher, 1984. p. 15-47.

FREIRE, P. Professora sim, tia não: cartas a quem ousa ensinar. São Paulo: Olho D’Água, 1997.

FREITAS, N. K. Inclusão socioeducativa na escola: avaliação do processo e dos alunos. Ensaio: Avaliação e Políticas Públicas em Educação, v. 16, n. 60, p. 323-336, jul 2008. http://doi.org/10.1590/S0104-40362008000300002

JARDILINO, J. R. L. A pesquisa e o cotidiano escolar: uma ação colaborativa? EccoS Revista Cientifica, v. 7, n. 2, p. 239-49, jul./dez. 2005.

LIEBERMAN, A. Collaborative research: working with, not working on. Educational Leadership, v. 43, n. 5, p. 29-32, 1986.

MORIN, E. Introdução ao pensamento complexo. Porto Alegre: Sulina, 2006.

SANTOS, M. P. Dialogando sobre inclusão em educação: contando casos (e descasos). Curitiba: CRV, 2013. 
SANTOS, M. P. Ciclo de formação de professores sobre inclusão em educação: em direção a uma perspectiva omnilética. In: Reunião Nacional da ANPEd, 36., 2013, Goiânia. Anais... Rio de Janeiro: Anped, 2013. Disponível em: $<$ http://36reuniao.anped.org.br/pdfs_trabalhos_aprovados /gt15_ trabalhos_pdfs/gt15_2901_texto.pdf>. Acesso em: 20 jan. 2014.

SAWAIA, B. As artimanhas da exclusão: análise psicossocial e ética da desigualdade social. Petrópolis: Vozes, 2008.

SILVA, M. C. V.; MELETTI, S. M. F. Avaliação em larga escala de alunos com necessidades educacionais especiais no município de Londrina (PR). Revista Educação Especial, v. 25, n. 44, p. 417-34, set./dez. 2012. http://doi.org/10.5902/1984686X6531

SOUSA, S. Z. L. Avaliação e gestão da educação básica: da competição aos incentivos. In: DOURADO, L. F. (Org.). Políticas e gestão da educação no Brasil: novos marcos regulatórios. São Paulo: Xamã, 2009. p. 31-48.

\section{Informações das autoras}

Mylene Cristina Santiago: Doutora em Educação pela Universidade Federal do Rio de Janeiro. Professora Adjunta do departamento Sociedade, Educação e Conhecimento da Faculdade de Educação da Universidade Federal Fluminense. Contato: mylenesantiago87@gmail.com

Mônica Pereira dos Santos: Doutora em Psicologia e Educação Especial pela Universidade de Londres. Professora Associada do departamento Fundamentos da Educação da Faculdade de Educação da Universidade Federal do Rio de Janeiro. Contato: monicapes@globo.com

Sandra Cordeiro de Melo: Doutora em Educação pela Universidade Federal do Rio de Janeiro. Professora Adjunta do departamento Fundamentos da Educação da Faculdade de Educação da Universidade Federal do Rio de Janeiro. Contato: sandracmello@gmail.com 